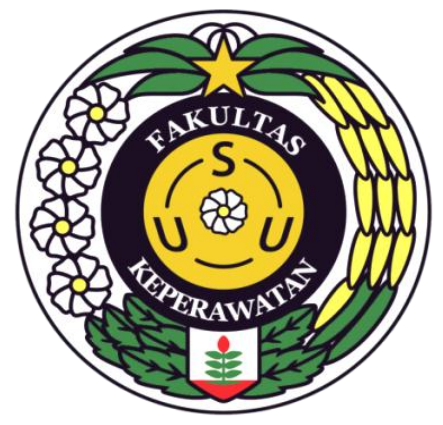

KAJIAN ILMIAH

PENGARUH PROMOSI KESEHATAN TERHADAP PENINGKATAN KESEHATAN MASYARAKAT

DISUSUN OLEH :

ALI SARJUNI PADANG 197046017

alisarjunipadang@gmail.com

PROGRAM STUDI MAGISTER ILMU KEPERAWATAN FAKULTAS KEPERAWATAN UNIVERSITAS SUMATERA UTARA MEDAN 2019 


\title{
PENGARUH PROMOSI KESEHATAN TERHADAP PENINGKATAN KESEHATAN MASYARAKAT
}

\author{
ALI SARJUNI PADANG \\ 197046017 \\ alisarjunipadang@gmail.com
}

\begin{abstract}
Abstrak
Latar belakang : Perkembangan Promosi Kesehatan tidak terlepas dariperkembangan sejarah Kesehatan Masyarakat di Indonesia dan dipengaruhi juga oleh perkembangan Promosi Kesehatan International yaitu dimulainya program Pembangunan Kesehatan Masyarakat Desa (PKMD) pada tahun 1975 dan tingkat Internasional tahun 1978Deklarasi Alma Ata tentang Primary Health Care tersebut sebagai tonggak sejarah cikal bakalPromosi Kesehatan (Departemen Kesehatan, 1994). Green dan Kreuter (2005) menyatakan bahwa "Promosi kesehatan adalah kombinasiupaya-upaya pendidikan, kebijakan (politik), peraturan, dan organisasi untuk mendukungkegiatankegiatan dan kondisi-kondisi hidup yang menguntungkan kesehatan individu,kelompok, atau komunitas".
\end{abstract}

Tujuan : tujuan dari penelitian ini adalah untuk mengetahui bagaimana pengaruh promosi kesehatan terhadap peningkatan kesehatan masyarakat.

Metode : Metode penelitian yang digunakan pada penelitian ini adalah dengan kajian pustaka terhadap beberapa jurnal yang berhubungan dengan pengaruh promosi kesehatan terhadap peningkatan kesehatan masyarakat, dan beberapa jurnal yang digunakan dalam melakukan literature review adalah tahun 2011 sampai 2019 sebanyak 10 jurnal

Hasil : dari 5 jurnal yang dilakukan sebagai pembanding, keseluruhanya menunjukkan ada peningkatan perilaku sehat sebelum dan sesudah dilakukanya promosi kesehatan.

Rekomendasi : Bagi seluruh staff dalam layanan kesehatan agar meningkatkan kualitas dan frekuensi promosi kesehatan di masyarakat, karna metode ini sangatlah efektif dalam memberikan pemahaman tentang hidup sehat dan meningkatkan pengetahuan masyarakat tentang hidup sehat.

Kata kunci : Promosi, masyarakat, staff kesehatan 


\section{A. Latar belakang}

Perkembangan Promosi Kesehatan tidak terlepas dariperkembangan sejarah Kesehatan Masyarakat di Indonesia dan dipengaruhi juga oleh perkembangan Promosi Kesehatan International yaitu dimulainya program Pembangunan Kesehatan Masyarakat Desa (PKMD) pada tahun 1975 dan tingkat Internasional tahun 1978Deklarasi Alma Ata tentang Primary Health Care tersebut sebagai tonggak sejarah cikal bakalPromosi Kesehatan (Departemen Kesehatan, 1994).

Green dan Kreuter (2005) menyatakan bahwa "Promosi kesehatan adalah kombinasiupaya-upaya pendidikan, kebijakan (politik), peraturan, dan organisasi untuk mendukungkegiatan-kegiatan dan kondisi-kondisi hidup yang menguntungkan kesehatan individu,kelompok, atau komunitas".Sedangkan Kementerian/Departemen Kesehatan Republik Indonesia merumuskanpengertian promosi kesehatan sebagai berikut: "Upaya untuk meningkatkan kemampuanmasyarakat dalam mengendalikan faktor-faktor kesehatan melalui pembelajaran dari, oleh,untuk dan bersama masyarakat, agar mereka dapat menolong dirinya sendiri, sertamengembangkan kegiatan yang bersumberdaya masyarakat, sesuai sosial budaya setempatdan didukung oleh kebijakan publik yang berwawasan kesehatan." Hal tersebut tertuangdalam Keputusan Menteri Kesehatan No. 1114/Menkes/SK/VIII/2005

Peran perawat menurut Pender (2015), setiap keluarga dan komunitas memiliki keragaman suku, budaya, dan letak geografis. Perawat harus dapat mempromosikan kesehatan dengan menyesuaikan bahasa dan budaya yang ada agar dapat diterima oleh kelompok masyarakat. Selain itu perawat perlu memahami model dan teori konseptual mengenai keperawatan keluarga, keperawatan komunitas, dan ilmu sosial keluarga dan komunitas. Hal tersebut bertujuan untuk mengembangkan pengetahuan dan pemahaman masyarakat mengenai kesehatan keluarga dan komunitas.

Berbagai masalah kesehatan dalam masyarakat seringkali disebabkan oleh rendahnya pengetahuan dan kesadaran, ketidakmampuan, serta rendahnya motivasi masyarakat mengenai pentingnya tindakan pencegahan penyakit. Fenomena tersebut tentunya tidak akan merubah kondisi kesehatan masyarakat di Indonesia karena masyarakat cenderung hanya memedulikan pengobatan daripada pencegahan penyakit. Untuk memperbaiki kondisi tersebut, perawat tentu turut aktif dalam memperbaiki pola pikir dan perilaku masyarakat terhadap perilaku kesehatan yang benar, yaitu dengan 
dilakukannya promosi kesehatan. Promosi kesehatan cenderung tertuju pada perawat komunitas, karena memiliki fokus terhadap upaya promotif dan preventif. Dalam upaya promosi kesehatan tersebut terjadi proses alih peran perawat kesehatan komunitas kepada individu, keluarga, atau kelompok sehingga diharapkan dapat memandirikan masyarakat terkait pola pikir maupun perilaku kesehatan yang baik (Jaji, 2012).

Peran perawat tidak hanya terfokus sebagai care giver, namun juga sangat penting untuk dapat mendidik masyarakat dalam memperbaiki perilaku sehat dengan dilakukan penyuluhan kesehatan maupun pemberdayaan masyarakat supaya mereka dapat lebih mandiri dan peduli mengenai pentingnya tindakan pencegahan sakit daripada pengobatan saat sakit.

Beberapa prinsip praktik keperawatan komunitas menurut Setyowati (2007), yaitu :

1. Kemanfaatan, yang berarti intervensi yang dilakukan harus memberikan manfaat sebesar-besarnya bagi komunitas.

2. Prinsip otonomi, yaitu komunitas memberi komunitas kebebasan untuk melakukan atau memilih alternatif terbaik yang disediakan komunitas.

3. Prinsip keadilan, yaitu berupaya melakukan tindakan sesuai dengan kemampuan dan kapasitas komunitas.

4. Secara mendasar, dalam promosi kesehatan perawat memiliki peran sebagai (Setyowati, 2007):

5. Pemberi layanan keperawatan. Perawat memberikan pelayanan keperawatan secara langsung maupun tidak langsung melalui pendekatan proses keperawatan kepada individu, keluarga, maupun kelompok masyarakat.

6. Pendidik. Perawat memberikan pendidikan kesehatan kepada klien secara mandiri maupun melibatkan kader kesehatan.

7. Pengelola. Perawat merencanakan, mengorganisasi, menggerakkan, dan mengevaluasi pelayanan keperawatan secara langsung dan tidak langsung dengan melibatkan peran aktif masyarakat dalam kegiatan keperawatan komunitas.

8. Konselor. Perawat memberi konseling atau bimbingan kepada kader, keluarga, atau kelompok mengenai masalah kesehatan komunitas.

9. Advokator. Perawat harus melindungi dan memfasilitasi keluarga maupun masyarakat dalam pelayanan keperawatan komunitas. 
10. Peneliti. Perawat melakukan penelitian untuk dapat mengembangkan keperawatan komunitas.

Promosi kesehatan bagi perawat dapat diwujudkan dengan diselenggarakannya berbagai kegiatan seperti melakukan kunjungan disuatu keluarga (home visit), pemberdayaan suatu komunitas masyarakat, penyuluhan di UKS sekolah atau balai desa, maupun melalui media internet supaya dapat menjangkau komunitas yang lebih luas (Saragih, 2017; Setyowati, 2007).

\section{B. Tujuan}

Tujuan dari penelitian ini adalah untukmengetahui bagaimna pengaruh perawat dalam promosi kesehatan terhadap peningkatan kesehatan masyarakat.

\section{Metode}

Metode penelitian yang digunakan pada penelitian ini adalah dengan kajian pustaka terhadap beberapa jurnal yang berhubungan dengan pengaruh promosi kesehatan terhadap peningkatan kesehatan masyarakat, dan beberapa jurnal yang digunakan dalam melakukan literature review adalah tahun 2011 sampai 2019 sebanyak 10 jurnal.

\section{Hasil}

Hasil dari Beberapa Judul jurnal yang diambil dalam kajian ini adalah :

1. Pengaruh promosi kesehatan terhadap pengetahuan siswa kelas 4,5 dan 6 dalam upaya pencegahan kecacingan di sdn 2 keteguhan teluk betung barat oleh niluh ita pasyanti, fitria saftarina, evi kurniawaty

2. Pengaruh penyuluhan dengan metode ceramah dan diskusi terhadap peningkatan pengetahuan dan sikap anak tentang phbs di sekolah dasar negeri 065014 kelurahan namogajah kecamatan medan tuntungan tahun 2013 oleh zul salasa akbar lubis, namora lumongga lubis, eddy syahrial

3. Pengaruh promosi kesehatan metode audio visual dan metode buku saku terhadap peningkatan pengetahuan penggunaan monosodium glutamat (msg) pada ibu rumah tangga oleh surya wibowo, dyah suryani

4. Pengaruh promosi kesehatan reproduksi remaja terhadap 
pengetahuan dan sikap siswa smp negeri 08 bitung oleh frantin f. karundeng, sesca d. solang, henry s. imbar

5. Pengaruh promosi kesehatan terhadap pengetahuan,sikap dan perilaku masyarakat tentang filariasis (effect of health promotion to community knowledge, attitude and behavior of filariasis) oleh santoso, yulian taviv, yahy1, rika mayasari

6. Pengaruh penyuluhan kesehatan tentang kecacingan terhadap pengetahuan dan sikap siswa madrasah ibtidaiyah an nur kelurahan pedurungan kidul kota semarang oleh cicilia presska a.k, trixie salawati, rahayu astuti

7. Pengaruh pendidikan gizi terhadap pengetahuan dan sikap tentang gizi anak sekolah dasar oleh nuryanto1, adriyan pramono1, niken puruhita1, siti fatimah muis1

8. Pengaruh penyuluhan dengan media audio visual terhadap peningkatan pengetahuan sikap dan perilaku ibu balita gizi kurang dan buruk di kabupaten kota waringin barat provinsi kalimantan tengah oleh Ira Rahmawati

9. Pengaruh sosialisasi sop apd dengan perilaku perawat dalam penggunaan APD (handscoon, masker, gown) di rsud dr. h. soewondo oleh reny yulita sari, erni suprapti, achmad solechan

10. Analisis promosi kesehatan berdasarkan ottawa charter di rs onkologi surabaya oleh zelbi windarini tiraihati

\section{E. Pembahasan}

Berdasarkan hasil tinjauan yang didapatkan dari beberapa jurnal diatas, bahwa peran Promosi Kesehatan sangat diperlukan dalam memberikan pengetahuan tentang kesehatan di kalangan masyrakat.

Menurut penelitian niluh ita pasyanti, fitria saftarina, evi kurniawaty yang berjudul Pengaruh promosi kesehatan terhadap pengetahuan siswa kelas 4, 5 dan 6 dalam upaya pencegahan kecacingan di sdn 2 keteguhan teluk betung barat dengan metode penelitian eksperimen semu atau quasi eksperiment dengan rancangan pretestposttest grup desain pada 69 siswa di bulan November 2014 menyatakan bahwa terdapat peningkatan hasil pengetahuan sesudah dilakukan promosi kesehatan, nilai $\mathrm{p}=$ 0,001 
Dari penelitian surya wibowo dan dyah suryani yang berjudul Pengaruh promosi kesehatan metode audio visual dan metode buku saku terhadap peningkatan pengetahuan penggunaan monosodium glutamat ( $\mathrm{msg}$ ) pada ibu rumah tangga dengan desain peneitian quasi experimental dengan rancangan penelitian one-group pretestpostest design. Subyek penelitian ini adalah ibu rumah tangga yang berjumlah 60 orang. Menyatakan bahwa terdapat pengaruh promosi kesehatan baik metode audio visual dengan $\mathrm{p}=0,00$, maupun metode buku saku dengan $\mathrm{p}=0,00$, terhadap peningkatan pengetahuan penggunaan MSG. Tidak terdapat perbedaan rerata antara kelompok perlakuan metode audio visual dan kelompok perlakuan metode buku saku dengan $\mathrm{p}=$ 0,817 .

Menurut Penelitian frantin f. karundeng, sesca d. solang, henry s. imbar dengan judul penelitian Pengaruh promosi kesehatan reproduksi remaja terhadap pengetahuan dan sikap siswa smp negeri 08 bitung dengan desain penelitian pre-eksperimental, dengan desain penelitian One-Group Pretest-Post test jumlah populasi 169 siswa dan sampel 63 responden. Teknik analisa data menggunakan uji Paired Samples T-Test. mengemukakan bahwa ada perubahan nilai mean skor pengetahuan siswa sebelum dan sesudah promosi kesehatan 5,54 dengan $\mathrm{p}=0,0001$; thitung $-37,410$ dan sikap siswa sebelum dan sesudah promosi kesehatan 6,46 dengan $\mathrm{p}=0,0001$; thitung $-37,873$ maka Ho ditolak dan Ha diterima. Hal ini memberikan makna bahwa ada pengaruh promosi kesehatan reproduksi remaja terhadap pengetahuan dan sikap siswa SMP Negeri 08 Bitung sehingga disarankan promosi kesehatan reproduksi remaja terus ditingkatkan melalui pendidikan yang diberikan melalui program puskesmas, pendidikan disekolah, keluarga dan masyarakat.

Berdasaran peneitian santoso, yulian taviv, yahya, rika mayasari yang berjudul judul Pengaruh promosi kesehatan terhadap pengetahuan,sikap dan perilaku masyarakat tentang filariasis (effect of health promotion to community knowledge, attitude and behavior of filariasis) denga metode penelitian kuasi eksperimen, yaitu dengan melakukan penilaian pengetahuan, sikap dan perilaku penduduk terhadap filarisis sebelum dan setelah mendapatkan promosi kesehatan. Jumlah penduduk yang diwawancarai sebanyak 117 responden menyatakan bahwa Tingkat pengetahuan responden dengan kategori tinggi tentang filariasis meningkat setelah kegiatan promkes dari $30,8 \%$ menjadi 59,8\%. Proporsi sikap responden dengan kategori baik terhadap 
kegiatan penanggulangan filariasis mengalami peningkatan setelah kegiatan promkes dari $62,4 \%$ menjadi $79,5 \%$. Perilaku minum obat responden mengalami peningkatan setelah promkes dari $70,1 \%$ menjadi $88,9 \%$.

Dari penelitian cicilia presska a.k, trixie salawati, rahayu astuti yang bejudul Pengaruh penyuluhan kesehatan tentang kecacingan terhadap pengetahuan dan sikap siswa madrasah ibtidaiyah an nur kelurahan pedurungan kidul kota semarang dengan desain penelitian eksperimen semu, dengan menggunakan rancangan pre test post test design menyatakan bahwa Ada perbedaan secara signifikan antara pengetahuan dan sikap sebelum dan sesudah intervensi pada masing-masing kelompok. Selanjutnya ada perbedaan secara signifikan antara peningkatan pengetahuan dan sikap antara kelompok yang diintervensi menggunakan cerita bergambar dengan ceramah

\section{F. Kesimpulan}

Dari beberapa hasil penelitian diatas menunjukkan bahwa manfaat promosi kesehatan sangatlah di butuhkan di kalangan masyarakat, terutama bagi masyarakat dengan pendidikan rendah, kegiatan ini sangatlah memberikan manfaat dalam meningkatkan pengetahuan masyarakat dalam meningkatan pengetahuan tetang kesehatan. Hal ini akan memberikan dampak terhadap pola hidup sehat.

\section{G. Rekomendasi}

Bagi seluruh staff dalam layanan kesehatan agar meningkatkan kualitas dan frekuensi promosi kesehatan di masyarakat, karna metode ini sangatlah efektif dalam memberikan pemahaman tentang hidup sehat dan meningkatkan pengetahuan masyarakat tentang hidup sehat. 


\section{DAFTAR PUSTAKA}

Efendi Ferry dan Makhfudli. (2009). Keperawatan Kesehatan Komunitas Teori Dan Praktek Dalam Keperawatan. Jakarta : Salemba Medika

Frantin F dkk (2015) Pengaruh promosi kesehatan reproduksi remaja terhadap pengetahuan dan sikap siswa smp negeri 08 bitung. Jurnal

Keputusan Menteri Kesehatan Republik Indonesia. (2005). Nomor : 1193/MENKES/SK/X/2004 tentang Promosi Kesehatan . Jakarta : Departemen Kesehatan RI

Kusnanto.(2004). Pengantar Profesi dan Praktik Keperawatan Profesional. Jakarta: EGC

Kementerian Kesehatan RI (2011). Promosi kesehatan di daerah bermasalah kesehatan. Jakarta

Kementerian Kesehatan RI (2016). Promosi Kesehatan.Modul bahan ajar cetak keperawatan

Maulana H. D. (2009). Promosi Kesehatan. Edisi 1. Jakarta : EGC.

Notoadmodjo S. (2010). Promosi kesehatan Teori dan Aplikasi. Edisi Revisi. Jakarta : Rineka Cipta.

Peraturan Menteri Kesehatan Republik Indonesia Nomor 17 Tahun 2013 Tentang Tentang Izin dan penyelenggaraan Praktik Perawat

Pasyanti T dkk (2012) Pengaruh promosi kesehatan terhadap pengetahuan siswa kelas 4, 5 dan 6 dalam upaya pencegahan kecacingan di sdn 2 keteguhan teluk betung barat. Jurnal

Presska C dkk (2013) yang bejudul Pengaruh penyuluhan kesehatan tentang kecacingan terhadap pengetahuan dan sikap siswa madrasah ibtidaiyah an nur kelurahan pedurungan kidul kota semarang. Jurnal

Santoso dkk (2016) Pengaruh promosi kesehatan terhadap pengetahuan,sikap dan perilaku masyarakat tentang filariasis (effect of health promotion to community knowledge, attitude and behavior of filariasis). Jurnal

Simamora,R.H. (2018) Penyuluhan kesehatan masyarakat: Penatalaksanaan perawatan penderita asam urat menggunakan media audiovisual : JPPM

Tiraihati, W.Z. (2017) Analisis Promosi Kesehatan Berdasarkan Ottawa Charter Di Rs Onkologi Surabaya

Wibowo S dan Suryani (2012) Pengaruh promosi kesehatan metode audio visual dan metode buku saku terhadap peningkatan pengetahuan penggunaan monosodium glutamat (msg) pada ibu rumah tangga. Jurnal 